Article

\title{
Antifeedant Triterpenoids from the Seeds and Bark of Lansium domesticum cv Kokossan (Meliaceae)
}

\author{
Tri Mayanti ${ }^{1}$, Roekmiati Tjokronegoro ${ }^{1}$, Unang Supratman ${ }^{1, *}$, Mat Ropi Mukhtar ${ }^{2}$, \\ Khalijah Awang ${ }^{2}$ and A. Hamid A. Hadi ${ }^{2}$
}

1 Department of Chemistry, Faculty of Mathematics and Natural Sciences, Padjadjaran University, Jatinangor 45363, Indonesia

2 Department of Chemistry, Faculty of Science, University of Malaya, Kuala Lumpur 50603, Malaysia; E-Mails: matropi@um.edu.my (M.R.M.); khalijah@um.edu.my (K.A.); ahamid@um.edu.my (A.H.A.H.)

* To whom correspondence should be addressed; E-Mail: u_supratman@unpad.ac.id; Tel.: 62-22-7794391; Fax: 62-22-7794391.

Received: 31 December 2010; in revised form: 28 February 2011 / Accepted: 2 March 2011 / Published: 29 March 2011

\begin{abstract}
Two tetranortriterpenoids, kokosanolide A (1) and C (2) were isolated from the seeds and three onoceranoid-type triterpenoids: kokosanolide B (3), 8,14-secogammacera7,14-diene-3,21-dione (4) and a 1.5:0.5 mixture of 8,14-secogammacera-7,14(27)-diene3,21-dione (5) and compound 4 were isolated from the bark of kokossan (Lansium domesticum). Complete ${ }^{1} \mathrm{H}$ - and ${ }^{13} \mathrm{C}-\mathrm{NMR}$ data of the triterpenoids 1-5 are reported. The triterpenoids' structures were elucidated primarily by means of high field 1D- and 2DNMR, IR and HRMS spectral data. Triterpenoids 1-5 exhibited moderate to strong antifeedant activity against the fourth instar larvae of Epilachna vigintioctopunctata.
\end{abstract}

Keywords: kokosanolides; tetranortriterpenoid; onoceranoid; Lansium domesticum; meliaceae; antifeedant activity

\section{Introduction}

Lansium domesticum cv Kokossan (family Meliaceae) is a higher tree, commonly called "kokosan" in Indonesia and widely distributed in Southeast Asian countries [1]. This plant has been reported to 
produce fruits and contain a bitter seed substance with antifeedant activity [2]. Previous phytochemical studies on L. domesticum reported the presence of tetranortriterpenoids [3-5], triterpenoid glycosides [6], onoceranoid-type triterpenoids [1] and onocerandiendione-type triterpenoids [5].

During the course of our continuing search for novel antifeedant compounds from tropical Meliaceae plants, the methanol extract of $L$. domesticum showed strong antifeedant activity against the fourth instar larvae of Epilachna vigintioctopunctata. Herein, we report the ${ }^{1} \mathrm{H}$ and ${ }^{13} \mathrm{C}$ NMR data and structural elucidation for these compounds 1-5 isolated from seed and bark extracts of the plant. The structures of compounds 1, 3 and 5 were established previously by X-ray diffraction [7-9].

Figure 1. Structure of compounds 1-5.
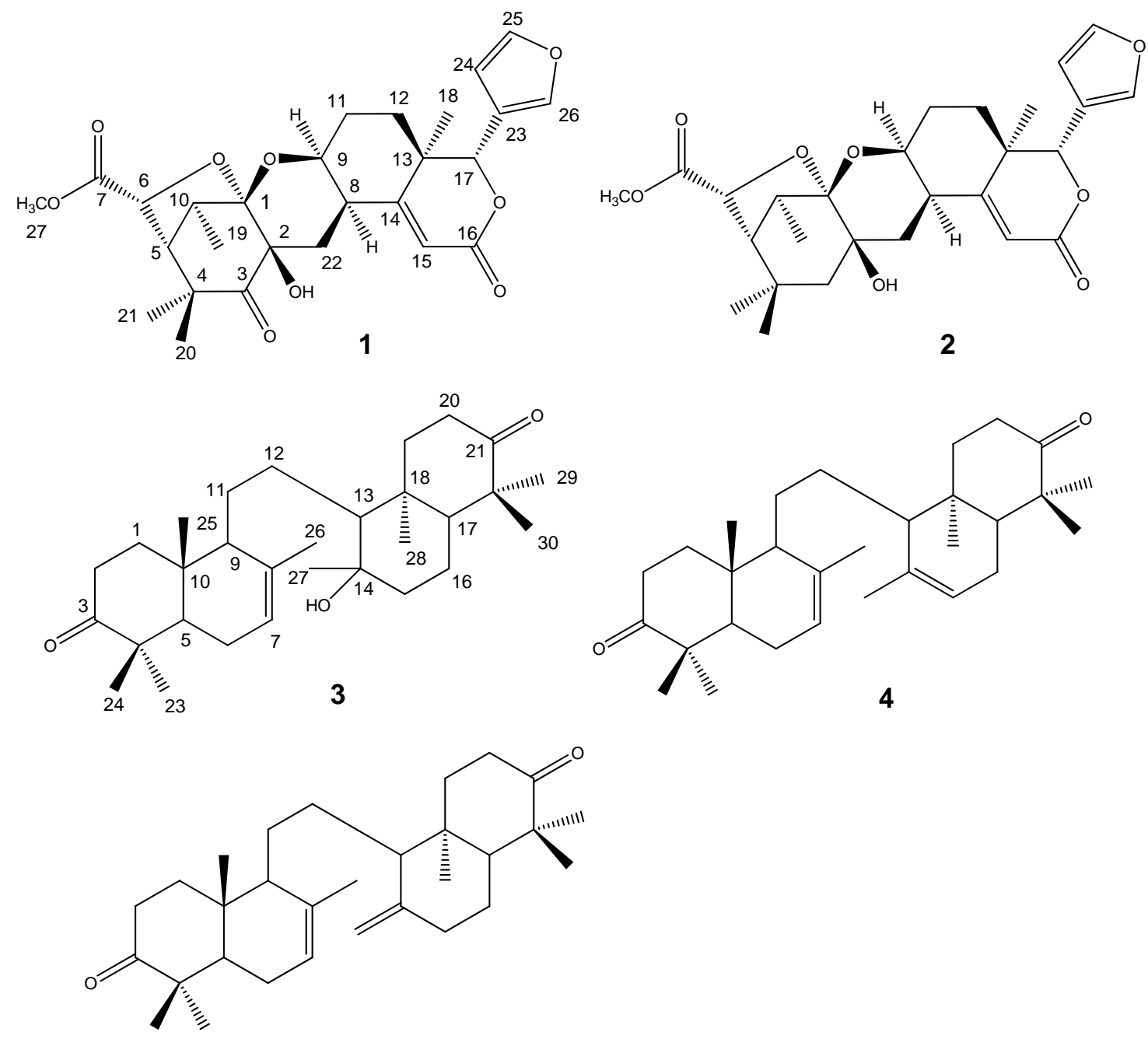

5

\section{Results and Discussion}

Liquid-liquid partitioning of the $\mathrm{MeOH}$ extract of the seed of L. domesticum cv Kokossan into $n$ hexane, EtOAc and aqueous $\mathrm{MeOH}$ fractions gave the $n$-hexane fraction $(4 \mathrm{~g})$ as the most active one, with $100 \%$ antifeedant activity at $1 \%$ concentration. Purification of the $n$-hexane fraction using silica gel 60 open column chromatography led to the isolation of compounds 1 and 2 . In addition, the $\mathrm{MeOH}$ extract of the bark of $L$. domesticum was partitioned between $n$-hexane and ethyl acetate to give the 
ethyl acetate fraction. A crude ethyl acetate fraction was subjected to vacuum column chromatography on silica gel 60 and further purified by silica gel column chromatography to yield compounds 3-5.

Kokosanolide A (1) was obtained as a white needle-like crystals, m.p. $178-180{ }^{\circ} \mathrm{C}$, from $n$-hexaneEtOAc. Its molecular formula was established to be $\mathrm{C}_{27} \mathrm{H}_{32} \mathrm{O}_{9}$ by LC-ESI-MS data $(\mathrm{m} / \mathrm{z} 500.8093$, $[\mathrm{M}+\mathrm{H}]^{+}$), which combined with the ${ }^{1} \mathrm{H}$ - and ${ }^{13} \mathrm{C}-\mathrm{NMR}$ spectral data (Table 1), thus indicated 12 degrees of unsaturation. The UV spectrum showed an absorption maximum at $282 \mathrm{~nm}(\varepsilon$ 4,600), indicating the presence of an $\alpha-\beta$-unsaturated ketone. The IR spectrum showed bands which were ascribable to hydroxyl $\left(v_{\max } 3,427 \mathrm{~cm}^{-1}\right)$, a ketone $\left(v_{\max } 1,753 \mathrm{~cm}^{-1}\right)$, unsaturated ketone $\left(v_{\max } 1,709\right.$ $\left.\mathrm{cm}^{-1}\right)$, isolated double bond $\left(v_{\max } 1,631 \mathrm{~cm}^{-1}\right)$ and gem-dimethyl $\left(v_{\max } 1,449\right.$ and $\left.1,389 \mathrm{~cm}^{-1}\right)$ functionalities. The ${ }^{1} \mathrm{H}-\mathrm{NMR}$ spectrum showed the presence of three singlets $(\delta 0.98,1.07$ and 1.37) from tertiary methyl groups and one doublet at $\delta 1.13(\mathrm{~J}=8 \mathrm{~Hz})$ from a secondary methyl group which in turn was correlated to $\mathrm{H}-10(\delta 3.33,1 \mathrm{H}, \mathrm{q}, J=8 \mathrm{~Hz})$. A singlet appeared in the downfield region $(\delta$ 3.67) that was ascribed to the $\mathrm{C}-27$ methoxy protons. A detailed analysis of ${ }^{1} \mathrm{H}-\mathrm{NMR}$ spectrum showed characteristic signals of a tetranortriterpenoid skeleton with a $\beta$-substituted furan at $\delta 7.46,7.40$ and 6.43 and the presence of an olefinic signal of an $\alpha, \beta$-unsaturated ketone at $\delta 6.28(1 \mathrm{H}, \mathrm{s})[3,4]$. The ${ }^{13} \mathrm{C}-\mathrm{NMR}$, together with APT spectra, revealed 27 carbon signals, including characteristic signals due to a furan ring $[\delta 143.5(\mathrm{~d}), 141.9(\mathrm{~d}), 120.5(\mathrm{~s})$ and $110.8(\mathrm{~d})]$, a ketone $(\delta 208.5)$, two ester groups $(\delta$ 172.4 and 165.4), one oxygenated carbon $(\delta 108.4)$ and $\alpha, \beta$-unsaturated ketone $(\delta 168.6$ and 116.7), thus suggesting that 1 possesed a hexacyclic structure with a furan moiety. The ${ }^{1} \mathrm{H}-{ }^{1} \mathrm{H}$ COSY spectrum of 1 showed proton correlations of $\mathrm{H}_{5} / \mathrm{H}_{6}, \mathrm{H}_{9} / \mathrm{H}_{8} / \mathrm{H}_{22}, \mathrm{H}_{9} / \mathrm{H}_{11} / \mathrm{H}_{12}, \mathrm{H}_{5} / \mathrm{H}_{10} / \mathrm{H}_{19}$, and $\mathrm{H}_{24} / \mathrm{H}_{25}$, supporting the presence of tetranortriterpenoid structure with a furan ring [3-5]. The connectivity of these partial structures were established from the HMBC spectral data (Figure 2).

Figure 2. Selected HMBC $(\mathrm{H} \rightarrow \mathrm{C})(\mathbf{a})$ and NOESY $(\leftrightarrow)(\mathbf{b})$ correlations of kokosanolide A.
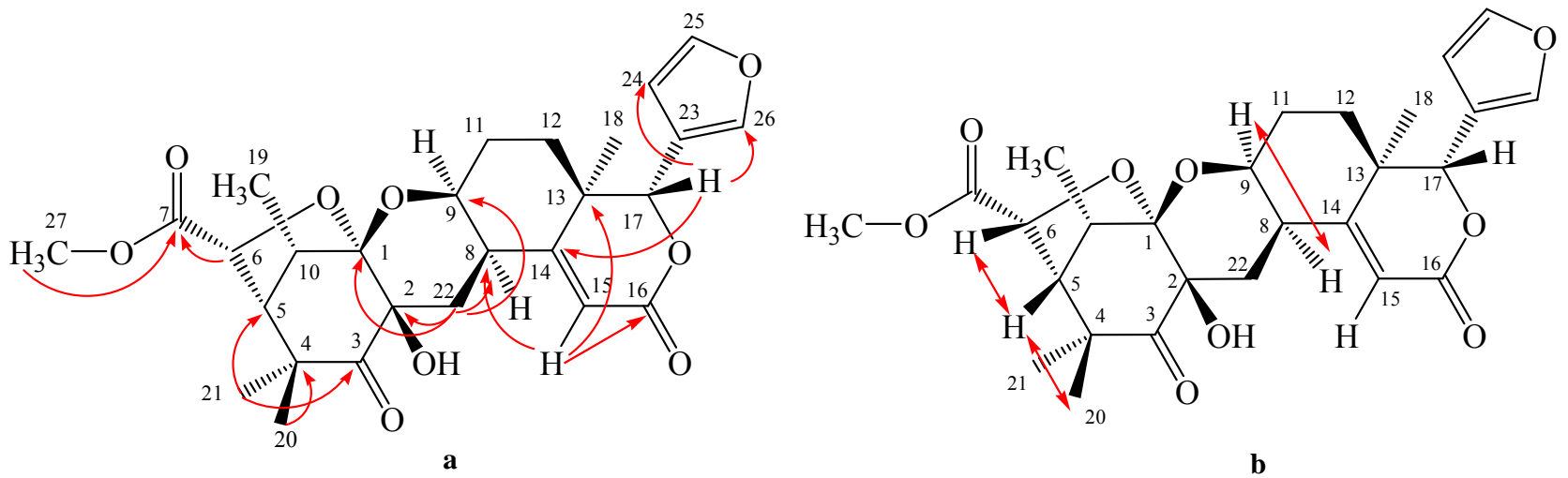

The oxygenated H-17 $(\delta$ 5.17) revealed correlations to C-23 $(\delta 120.5), \mathrm{C}-24(\delta 110.8)$ and C-26 $(\delta$ 141.9), indicating that the furan ring was located at C-17. The signals correlating H-15 $(\delta 6.28)$ with C-8 ( $\delta 34.6), C-13(\delta 39.6)$, and C-16 ( $\delta$ 165.4), suggested the presence of an $\alpha, \beta$-unsaturated $\delta$-lactone ring system. The positioning of the pyran ring was established by the correlation signals of H-22 $\left(\delta_{\mathrm{H}}\right.$

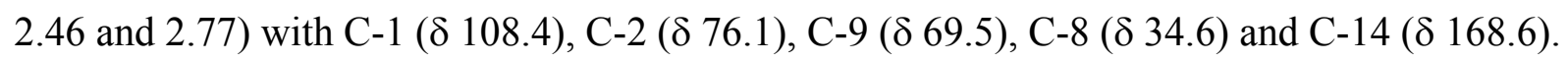


Table 1. NMR spectral data for compounds 1 and 2. ${ }^{\text {a }}$

\begin{tabular}{|c|c|c|c|c|c|}
\hline \multicolumn{4}{|c|}{1} & \multicolumn{2}{|r|}{2} \\
\hline Position & $\begin{array}{c}{ }^{13} \mathrm{C} \mathrm{NMR} \\
\delta_{\mathrm{C}} \text { (mult., ppm) } \\
\end{array}$ & $\begin{array}{c}{ }^{1} \mathrm{H} \text { NMR } \\
\delta_{\mathrm{H}}(\text { integral, mult., } J \mathrm{~Hz})\end{array}$ & $\begin{array}{c}\text { HMBC } \\
\left({ }^{1} \mathrm{H} \text { to }{ }^{13} \mathrm{C}\right)\end{array}$ & $\begin{array}{c}{ }^{13} \mathrm{C} \mathrm{NMR} \\
\delta_{\mathrm{C}} \text { (mult., ppm) } \\
\end{array}$ & $\begin{array}{c}{ }^{1} \mathrm{H} \text { NMR } \\
\delta_{\mathrm{H}}(\text { integral, mult., } J \mathrm{~Hz}) \\
\end{array}$ \\
\hline 1 & $108.4(\mathrm{~s})$ & - & - & $106.9(\mathrm{~s})$ & - \\
\hline 2 & $76.1(\mathrm{~s})$ & - & - & $76.1(\mathrm{~s})$ & - \\
\hline 3 & $208.6(\mathrm{~s})$ & - & - & $20.9(\mathrm{t})$ & $\begin{array}{l}1.71(1 \mathrm{H}, \mathrm{d}, 6.2) \\
2.18(1 \mathrm{H}, \mathrm{m})\end{array}$ \\
\hline 4 & $48.4(\mathrm{~s})$ & - & - & $47.8(\mathrm{~s})$ & - \\
\hline 5 & $56.4(d)$ & $2.27(1 \mathrm{H}, \mathrm{dd}, 4,7)$ & $1,3,4,10$ & $55.9(d)$ & $2.12(1 \mathrm{H}, \mathrm{dd}, 3.7,6)$ \\
\hline 6 & $77.4(d)$ & $4.81(1 \mathrm{H}, \mathrm{d}, 4)$ & $4,5,7$ & 76.7 (d) & $4.82(1 \mathrm{H}, \mathrm{d}, 4)$ \\
\hline 7 & $172.4(\mathrm{~s})$ & - & - & $171.9(\mathrm{~s})$ & - \\
\hline 8 & $34.6(d)$ & $2,64(1 \mathrm{H}, \mathrm{dd}, 5.3,6.5)$ & 14 & $34.4(d)$ & $2.31(1 \mathrm{H}, \mathrm{m})$ \\
\hline 9 & $69.5(d)$ & $4.39(1 \mathrm{H}, \mathrm{m})$ & 14 & $67.8(d)$ & $4.13(1 \mathrm{H}, \mathrm{m})$ \\
\hline 10 & $37.3(d)$ & $3.33(1 \mathrm{H}, \mathrm{q}, 8)$ & $2,4,5,19$ & 36.5 (d) & $3.29(1 \mathrm{H}, \mathrm{m})$ \\
\hline 11 & $25.3(\mathrm{t})$ & $1.79(1 \mathrm{H}, \mathrm{m})$ & $8,12,13$ & $26.8(\mathrm{t})$ & $1.76(1 \mathrm{H}, \mathrm{m})$ \\
\hline & & $1.91(1 \mathrm{H}, \mathrm{m})$ & - & & $1.90(1 \mathrm{H}, \mathrm{m})$ \\
\hline 12 & $27.8(\mathrm{t})$ & $1.26(1 \mathrm{H}, \mathrm{m})$ & $9,11,13,17$ & $29.4(t)$ & $1.23(1 \mathrm{H}, \mathrm{m})$ \\
\hline & & $1.74(1 \mathrm{H}, \mathrm{m})$ & - & & $1.72(1 \mathrm{H}, \mathrm{m})$ \\
\hline 13 & $39.6(\mathrm{~s})$ & - & - & $38.4(\mathrm{~s})$ & - \\
\hline 14 & $168.6(\mathrm{~s})$ & - & - & $167.4(\mathrm{~s})$ & - \\
\hline 15 & $116.7(d)$ & $6.28(1 \mathrm{H}, \mathrm{s})$ & $8,13,16$ & $117.4(\mathrm{~d})$ & $6.43(1 \mathrm{H}, \mathrm{s})$ \\
\hline 16 & $165.4(\mathrm{~s})$ & - & - & $165.4(\mathrm{~s})$ & - \\
\hline 17 & $81.5(d)$ & $5.17(1 \mathrm{H}, \mathrm{s})$ & $14,23,24,26$ & 81.7 (d) & $5.14(1 \mathrm{H}, \mathrm{s})$ \\
\hline 18 & $18.2(q)$ & $1.07(3 \mathrm{H}, \mathrm{s})$ & $12,13,14,17$ & $19.6(q)$ & $1.26(3 \mathrm{H}, \mathrm{s})$ \\
\hline 19 & $12.2(q)$ & $1.13(3 \mathrm{H}, \mathrm{d}, 8)$ & $1,5,10$ & $11.7(q)$ & $1.17(3 \mathrm{H}, \mathrm{d}, 7.8)$ \\
\hline 20 & $23.7(q)$ & $0.98(3 \mathrm{H}, \mathrm{s})$ & $3,4,5,21$ & $23.3(q)$ & $0.98(3 \mathrm{H}, \mathrm{s})$ \\
\hline 21 & $30.1(\mathrm{q})$ & $1.37(3 \mathrm{H}, \mathrm{s})$ & $3,4,5,20$ & 30.9 (q) & $1.37(3 \mathrm{H}, \mathrm{s})$ \\
\hline 22 & $25.4(\mathrm{t})$ & $2.46(1 \mathrm{H}, \mathrm{dd}, 7.5,5.3)$ & $1,2,3,8,9,14$ & $25.7(\mathrm{t})$ & $2.41(1 \mathrm{H}, \mathrm{m})$ \\
\hline & & $2.77(1 \mathrm{H}, \mathrm{dd}, 7.5,4.7)$ & - & - & $2.70(1 \mathrm{H}, \mathrm{m})$ \\
\hline 23 & $120.5(\mathrm{~s})$ & - & - & $119.7(\mathrm{~s})$ & - \\
\hline 24 & $110.8(d)$ & $6.43(1 \mathrm{H}, \mathrm{d}, 4.4)$ & $23,25,26$ & $110.2(\mathrm{~d})$ & $6.45(1 \mathrm{H}, \mathrm{s})$ \\
\hline 25 & $143.5(\mathrm{~d})$ & $7.40(1 \mathrm{H}, \mathrm{d}, 4.4)$ & $23,24,26$ & $142.8(\mathrm{~d})$ & $7.40(1 \mathrm{H}, \mathrm{s})$ \\
\hline 26 & $141.9(\mathrm{~d})$ & $7.47(1 \mathrm{H}, \mathrm{s})$ & $23,24,25$ & $141.4(\mathrm{~d})$ & $7.47(1 \mathrm{H}, \mathrm{s})$ \\
\hline $27-\mathrm{OCH}_{3}$ & $52.6(q)$ & $3.67(3 \mathrm{H}, \mathrm{s})$ & - & $52.2(\mathrm{q})$ & $3.68(3 \mathrm{H}, \mathrm{s})$ \\
\hline
\end{tabular}

${ }^{\mathrm{a}}$ Taken in $\mathrm{CDCl}_{3}$ at $500 \mathrm{MHz}$ for ${ }^{1} \mathrm{H}$ and at $125 \mathrm{MHz}$ for ${ }^{13} \mathrm{C}$. 
Other correlations of methyl signal at $\delta 0.98$ and 1.37 to $\mathrm{C}-3(\delta 208.6), \mathrm{C}-4$ (48.4) and C-5 $\left(\delta_{\mathrm{H}}\right.$ $56.4)$, suggesting that gem-dimethyl was located at C-4. The carbomethoxyl signal ( $\delta 3.67)$ and the signal of H-6 ( $\delta 4.81)$ were correlated to an ester carbonyl $(\delta 172.4)$, suggesting that an ester group was located at C-6. The relative configuration of 1 was elucidated by NOESY correlations as shown in Figure 2. NOESY correlation of H-8/H-9 suggesting that pyran ring should be $\beta$-orientation. Correlations between $\mathrm{H}-6 / \mathrm{H}-5 / \mathrm{H}-20$ indicated that methyl group and tetrahydrofuran ring should be $\alpha$ orientation. Thus, the gross structure of tetranortriterpenoid $\mathbf{1}$ was elucidated as a hexacyclic ring system. The structure and relative stereochemistry were further elucidated by using single-crystal Xray diffraction analysis [7]. An ORTEP drawing of $\mathbf{1}$ is shown in Figure 3. Consequently, the structure of tetranortriterpenoid 1 was established to be a tetranortriterpenoid and was named kokosanolide A.

Figure 3. ORTEP drawing for kokosanolide A reproduced from Mayanti et al. [7].

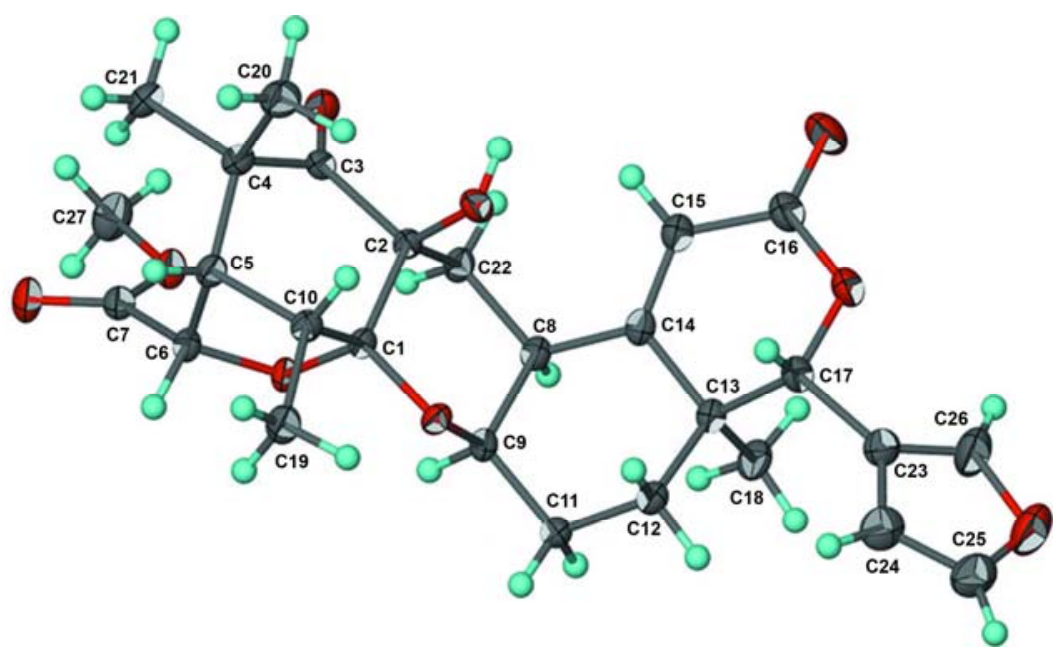

Kokosanolide C (2) was obtained as colorless needle-like crystals from $n$-hexane-EtOAc and decomposed during the measurement of its melting point. The UV spectrum showed an absorption maximum at $275 \mathrm{~nm}(\varepsilon 4,500)$, indicating the presence of an $\alpha$ - $\beta$-unsaturated ketone. The IR spectrum showed bands which were ascribable to hydroxyl $\left(v_{\max } 3,563 \mathrm{~cm}^{-1}\right)$, a ester carbonyl $\left(v_{\max } 1,758 \mathrm{~cm}^{-1}\right)$ and unsaturated ketone $\left(v_{\max } 1,704 \mathrm{~cm}^{-1}\right)$. The ${ }^{1} \mathrm{H}$ - and ${ }^{13} \mathrm{C}-\mathrm{NMR}$ (Table 1) spectra of 2 were quite similar to those of 1, except for the absence of the ketone signal at $\delta 208.5$ and appearance of a geminal proton signal at $\left[\delta_{\mathrm{H}} 2.18(1 \mathrm{H}, \mathrm{m}), 1.71(1 \mathrm{H}, \mathrm{m}) ; \delta_{\mathrm{C}} 20.9\right]$. In the $\mathrm{HMBC}$ spectrum of 2 , long range correlations were observed between the signals at $\delta 1.72$ and 2.18 and the carbon signals at $\delta$ 76.1 (C-2), 47.8 (C-4) and 55.9 (C-5), suggesting that compound 2 was a 3-deoxo derivative of compound 1 and it was thus named kokosanolide $\mathrm{C}$.

Kokosanolide B (3) was obtained as cubic crystals, m.p. $148-150{ }^{\circ} \mathrm{C}$, from $n$-hexane-EtOAc. The molecular formula of 3 was determined to be $\mathrm{C}_{30} \mathrm{H}_{48} \mathrm{O}_{3}$ by LC- ESI-MS data $\left(\mathrm{m} / \mathrm{z} 456.6892,[\mathrm{M}+\mathrm{H}]^{+}\right)$, and combined with the ${ }^{1} \mathrm{H}$ - and ${ }^{13} \mathrm{C}-\mathrm{NMR}$ spectral data (Table 2), thus required seven degrees of unsaturation. IR absorption bands at 3,749, 1,705, 1,384 and 1,261 $\mathrm{cm}^{-1}$ suggested the presence of hydroxyl, carbonyl, and gem-dimethyl functionalities, respectively. Analysis of ${ }^{1} \mathrm{H}$ - and ${ }^{13} \mathrm{C}-\mathrm{NMR}$ data, DEPT and the HMQC spectra of 3 revealed the presence of thirty signals: three $\mathrm{sp}^{2}$ and five $\mathrm{sp}^{3}$ quaternary carbons, one $\mathrm{sp}^{2}$ and four $\mathrm{sp}^{3}$ methines, nine $\mathrm{sp}^{3}$ methylenes, and eight methyl groups. Among them, one $\mathrm{sp}^{2}$ methine $\left(\delta_{\mathrm{C}} 121.7 ; \delta_{\mathrm{H}}(1 \mathrm{H}, 5.41, \mathrm{~m})\right.$ was ascribed to the isolated double bond, 
while two carbonyl carbons ( $\delta 216.9$ and $217.1 \mathrm{ppm})$ and one $\mathrm{sp}^{3}$ carbon $(\delta 74.0)$ were assigned to those bearing an oxygen atom (C-3, C-21 and C-14, respectively), suggesting that compound 3 was an onoceranoid-type triterpenoid [5]. The positions of the ketones, hydroxyl and isolated double bond were further determined by the COSY and HMBC experiments (Figure 4), H-7 ( $\delta$ 5.41) showed correlations to $\mathrm{C}-6(\delta 28.9), \mathrm{C}-9(\delta 55.5)$ and $\mathrm{C}-8(\delta 135.3)$, suggesting that an isolated double bond is located at $\mathrm{C}-7$ and $\mathrm{C}-8$. The methylene signals at $\mathrm{C}-2(\delta 2.23)$ revealed correlations to carbonyl signal at $\delta 216.9$, whereas $\mathrm{H}-5(\delta$ 1.57) was correlated to $\mathrm{C}-4(\delta 47.6)$ and $\mathrm{C}-3(\delta 216.9)$, indicating that one of the carbonyl moeity and gem-dimethyl are placed at C-3 and C-4, respectively. Furthermore, the methylene signals at C-20 ( $\delta 2.26)$ showed correlations to the carbonyl signal at $\delta 217.1$, whereas the methine signal at $\mathrm{C}-17(\delta 1.42)$ showed correlations to $\mathrm{C}-22(\delta 47.6)$ and $\mathrm{C}-21(\delta 217.1)$, thus suggesting the other carbonyl group and gem-dimethyls were located at C-21 and C-22, respectively. An oxygenated tertiary carbon signal was revealed to be $\mathrm{C}-14$ by the correlation between methine signal at $\mathrm{C}-13\left(\delta_{\mathrm{C}} 1.12\right)$ to oxygenated carbon at $\delta_{\mathrm{C}} 74.0 \mathrm{ppm}$ and correlation between methylene signals at C-15 $\left(\delta_{\mathrm{C}} 1.46\right)$ to oxygenated carbon at $\delta_{\mathrm{C}} 74.0 \mathrm{ppm}$. Thus, the structure of onoceranoidtype triterpenoid 3 was determined as 8,14-secogammacera-14-hydroxy-7-ene-3,21-dione and was named kokosanolide $\mathrm{B}$. The structure and relative stereochemistry were also elucidated by using single-crystal X-ray diffraction analysis [8]. An ORTEP drawing of 3 is shown in Figure 5.

Figure 4. Selected HMBC $(\mathrm{H} \rightarrow \mathrm{C})$ and $\operatorname{COSY}(\rightarrow)$ correlations for kokosanolide B.

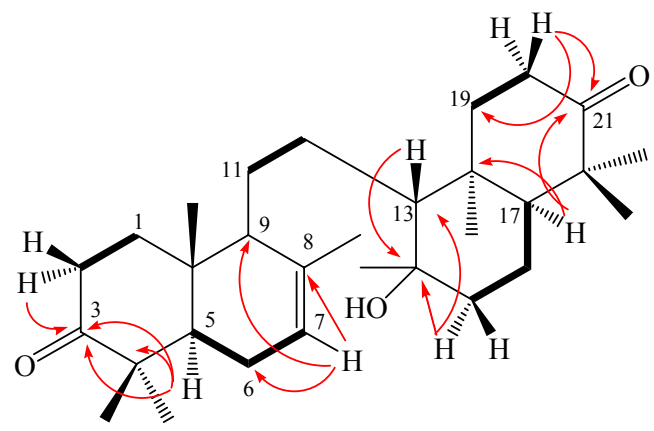

Figure 5. ORTEP drawing for kokosanolide B reproduced from Supratman et al. [8].

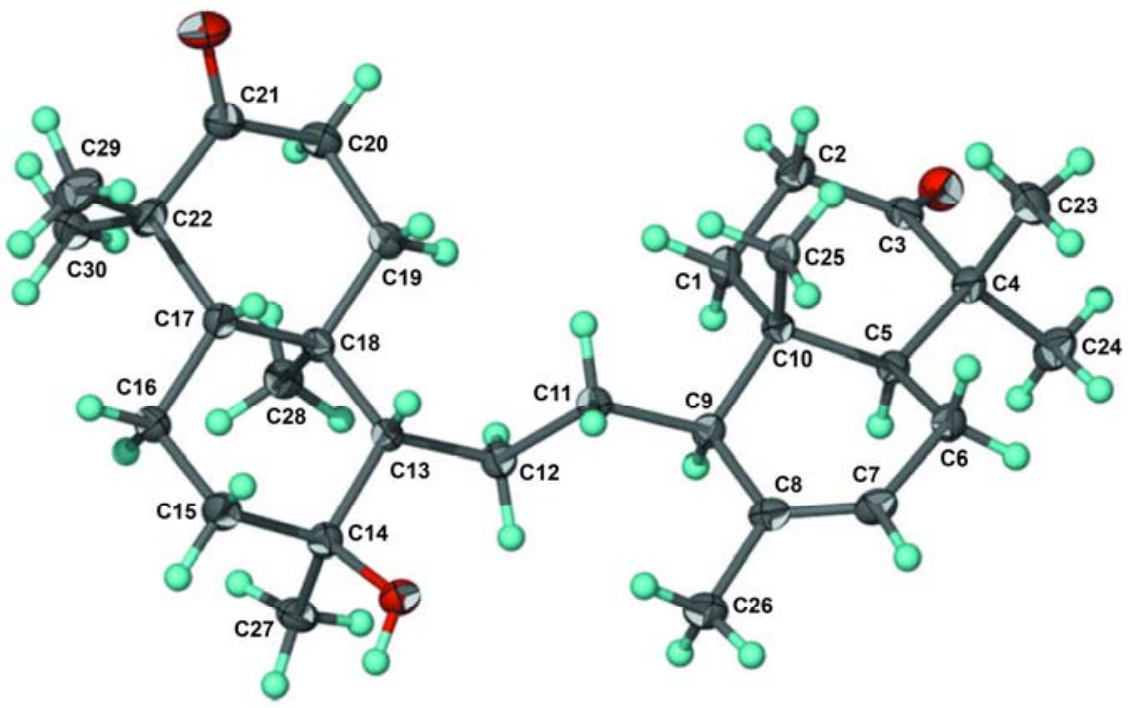


Table 2. NMR spectral data for compound 3 and 4 . $^{\text {a }}$

\begin{tabular}{|c|c|c|c|c|c|}
\hline & & 3 & & & 4 \\
\hline Position & $\begin{array}{c}{ }^{13} \mathrm{C} \text { NMR } \\
\delta_{\mathrm{C}} \text { (mult., ppm) }\end{array}$ & $\begin{array}{c}{ }^{1} \mathrm{H} \text { NMR } \\
\delta_{\mathrm{H}}(\text { integral, mult., } J \mathrm{~Hz})\end{array}$ & $\begin{array}{c}\mathrm{HMBC} \\
\left({ }^{1} \mathrm{H} \text { to }{ }^{13} \mathrm{C}\right)\end{array}$ & $\begin{array}{c}{ }^{13} \mathrm{C} \text { NMR } \\
\delta_{\mathrm{C}} \text { (mult., ppm) }\end{array}$ & $\begin{array}{c}{ }^{1} \mathrm{H} \text { NMR } \\
\delta_{\mathrm{H}}(\text { integral, mult., } J \mathrm{~Hz})\end{array}$ \\
\hline 1 & $38.5(\mathrm{t})$ & $1.91(1 \mathrm{H}, \mathrm{m}) ; 2.08(1 \mathrm{H}, \mathrm{m})$ & $2,3,10$ & $38.5(\mathrm{t})$ & $1.46(1 \mathrm{H}, \mathrm{m}) ; 2.09(1 \mathrm{H}, \mathrm{m})$ \\
\hline 2 & $34.8(\mathrm{t})$ & $2.23(1 \mathrm{H}, \mathrm{m}) ; 2.41(1 \mathrm{H}, \mathrm{m})$ & 3 & $34.8(\mathrm{t})$ & $2.24(1 \mathrm{H}, \mathrm{m}) ; 2.70(1 \mathrm{H}, \mathrm{m})$ \\
\hline 3 & $216.9(\mathrm{~s})$ & - & - & $216.9(\mathrm{~s})$ & - \\
\hline 4 & $47.6(\mathrm{~s})$ & - & - & $47.6(\mathrm{~s})$ & - \\
\hline 5 & $51.6(d)$ & $1.57(1 \mathrm{H}, \mathrm{m})$ & $9,10,24$ & $51.6(d)$ & $1.59(1 \mathrm{H}, \mathrm{dd}, 5,7)$ \\
\hline 6 & $28.9(\mathrm{t})$ & $1.12(1 \mathrm{H}, \mathrm{m}) ; 2.56(1 \mathrm{H}, \mathrm{m})$ & 7,10 & $30.1(\mathrm{t})$ & $1.33(1 \mathrm{H}, \mathrm{dd}, 7,10) ; 1.24(1 \mathrm{H}, \mathrm{dd}, 5,10)$ \\
\hline 7 & $121.7(d)$ & $5.41(1 \mathrm{H}, \mathrm{m})$ & 8 & $122.1(\mathrm{~d})$ & $5.43(1 \mathrm{H}, \mathrm{m})$ \\
\hline 8 & $135.3(\mathrm{~s})$ & - & - & $135.3(\mathrm{~s})$ & - \\
\hline 9 & $55.5(d)$ & $1.59(1 \mathrm{H}, \mathrm{m})$ & 26 & $55.6(d)$ & $1.65(1 \mathrm{H}, \mathrm{m})$ \\
\hline 10 & $36.6(\mathrm{~s})$ & - & - & $36.7(\mathrm{~s})$ & - \\
\hline 11 & $21.5(\mathrm{t})$ & $1.61(1 \mathrm{H}, \mathrm{m}) ; 2.41(1 \mathrm{H}, \mathrm{m})$ & 9 & $24.2(\mathrm{t})$ & $1.93(1 \mathrm{H}, \mathrm{m}) ; 2.40(1 \mathrm{H}, \mathrm{m})$ \\
\hline 12 & $21.5(\mathrm{t})$ & $1.62(1 \mathrm{H}, \mathrm{m}) ; 1.76(1 \mathrm{H}, \mathrm{m})$ & 9 & $24.2(\mathrm{t})$ & $1.93(1 \mathrm{H}, \mathrm{m}) ; 2.40(1 \mathrm{H}, \mathrm{m})$ \\
\hline 13 & $61.8(\mathrm{~d})$ & $1.12(1 \mathrm{H}, \mathrm{m})$ & 17 & $55.6(d)$ & $1.65(1 \mathrm{H}, \mathrm{m})$ \\
\hline 14 & $74.0(\mathrm{~s})$ & - & - & $135.3(\mathrm{~s})$ & - \\
\hline 15 & $44.2(\mathrm{t})$ & $1.46(1 \mathrm{H}, \mathrm{m}) ; 2.23(1 \mathrm{H}, \mathrm{m})$ & 14,17 & $122.1(\mathrm{~d})$ & $5.43(1 \mathrm{H}, \mathrm{m})$ \\
\hline 16 & $31.4(\mathrm{t})$ & $1.51(1 \mathrm{H}, \mathrm{m}) ; 1.84(1 \mathrm{H}, \mathrm{m})$ & 17 & $30.1(\mathrm{t})$ & $1.33(1 \mathrm{H}, \mathrm{dd}, 7,10) ; 1.24(1 \mathrm{H}, \mathrm{dd}, 5,10)$ \\
\hline 17 & $55.2(d)$ & $1.42(1 \mathrm{H}, \mathrm{m})$ & 18,22 & $51.6(d)$ & $1.59(1 \mathrm{H}, \mathrm{dd}, 5,7)$ \\
\hline 18 & $36.6(\mathrm{~s})$ & - & - & $36.7(\mathrm{~s})$ & - \\
\hline 19 & $38.4(\mathrm{t})$ & $1.78(1 \mathrm{H}, \mathrm{m}) ; 2.10(1 \mathrm{H}, \mathrm{m})$ & 21 & $38.5(\mathrm{t})$ & $1.46(1 \mathrm{H}, \mathrm{m}) ; 2.09(1 \mathrm{H}, \mathrm{m})$ \\
\hline 20 & $34.1(\mathrm{t})$ & $2.26(1 \mathrm{H}, \mathrm{m}) ; 2.73(1 \mathrm{H}, \mathrm{m})$ & 19,21 & $34.8(\mathrm{t})$ & $2.24(1 \mathrm{H}, \mathrm{m}) ; 2.70(1 \mathrm{H}, \mathrm{m})$ \\
\hline 21 & $217.1(\mathrm{~s})$ & - & - & $216.9(\mathrm{~s})$ & - \\
\hline 22 & $47.6(\mathrm{~s})$ & - & - & $47.6(\mathrm{~s})$ & - \\
\hline 23 & $25.1(q)$ & $1.04(3 \mathrm{H}, \mathrm{s})$ & 5,24 & $25.1(q)$ & $1.04(3 \mathrm{H}, \mathrm{s})$ \\
\hline 24 & $22.3(\mathrm{q})$ & $1.08(3 \mathrm{H}, \mathrm{s})$ & 23 & $22.3(\mathrm{q})$ & $1.09(3 \mathrm{H}, \mathrm{s})$ \\
\hline 25 & $13.4(q)$ & $0.96(3 \mathrm{H}, \mathrm{s})$ & $5,9,10$ & $13.5(q)$ & $0.97(3 \mathrm{H}, \mathrm{s})$ \\
\hline 26 & $22.3(q)$ & $1.77(3 \mathrm{H}, \mathrm{s})$ & 9 & $22.5(\mathrm{q})$ & $1.72(3 \mathrm{H}, \mathrm{s})$ \\
\hline 27 & $24.2(q)$ & $1.21(3 \mathrm{H}, \mathrm{s})$ & $13,14,15$ & $22.5(q)$ & $1.72(3 \mathrm{H}, \mathrm{s})$ \\
\hline 28 & $15.1(q)$ & $0.93(3 \mathrm{H}, \mathrm{s})$ & 13,17 & $13.5(q)$ & $0.97(3 \mathrm{H}, \mathrm{s})$ \\
\hline 29 & $21.4(\mathrm{q})$ & $1.02(3 \mathrm{H}, \mathrm{s})$ & $17,22,30$ & $25.1(\mathrm{q})$ & $1.04(3 \mathrm{H}, \mathrm{s})$ \\
\hline 30 & $26.5(q)$ & $1.09(3 \mathrm{H}, \mathrm{s})$ & 17,29 & $22.3(\mathrm{q})$ & $1.09(3 \mathrm{H}, \mathrm{s})$ \\
\hline
\end{tabular}

${ }^{\mathrm{a}}$ Taken in $\mathrm{CDCl}_{3}$ at $500 \mathrm{MHz}$ for ${ }^{1} \mathrm{H}$ and at $125 \mathrm{MHz}$ for ${ }^{13} \mathrm{C}$. 
8,14-Secogammacera-7,14-diene-3,2-dione (4) was obtained as a white needle-like crystals, m.p. 143-144 ${ }^{\circ} \mathrm{C}$, from $n$-hexane-EtOAc. The molecular formula of 4 was determined to be $\mathrm{C}_{30} \mathrm{H}_{46} \mathrm{O}_{2}$ by LC-ESI-MS data $\left.(\mathrm{m} / \mathrm{z} \text { 438.3745, }[\mathrm{M}+\mathrm{H}]]^{+}\right)$, which together with ${ }^{1} \mathrm{H}$ - and ${ }^{13} \mathrm{C}-\mathrm{NMR}$ spectral data (Table 2), requires eight degrees of unsaturation. Compound 4 showed no absorption maxima in the UV spectrum indicating the absence of a conjugated double bond. The IR spectrum showed bands which were ascribed to a ketone $\left(v_{\max } 1,708 \mathrm{~cm}^{-1}\right)$, isolated double bond $\left(v_{\max } 1,662 \mathrm{~cm}^{-1}\right)$ and gem-dimethyl ( $v_{\max }$ 1,430 and $1,360 \mathrm{~cm}^{-1}$ ). The ${ }^{13} \mathrm{C}$-NMR spectrum of 4 showed 15 signals, similar to those of kokosanolide B, suggesting that 4 has a symmetrical structure. The essential differences between the NMR spectra of 4 and kokosanolide B consisted of the absence of a hydroxyl group and appearance of a double bond $\left[\delta 5.43(1 \mathrm{H}, \mathrm{m}), \delta_{\mathrm{H}} 122.1\right.$ and 135.3] and fifteen carbon signals, suggesting that 4 was a dehydroxy derivative of kokosanolide $\mathrm{B}$. In order to determine the connectivity of the partial structure due to a newly double bond, HMBC experiments were carried out. The signal of olefinic proton $\mathrm{H}-15$ ( $\delta$ 5.43) was correlated to $\mathrm{C}-14(\delta$ 135.3), C-13 ( $\delta$ 55.6) and $\mathrm{C}-16$ ( $\delta 30.1)$, indicating that a new double bond was located at C-14 and C-15, suggesting that 4 has two similar unit structure. Consequently, compound 4 was identified as a 8,14-secogammacera-7,14-diene-3,21-dione [5].

Compound (5) was identified as 8,14-secogammacera-7,14(27)-diene-3,21-dione. It was isolated together with compound 4 with a ratio of 1.5:0.5. The ${ }^{1} \mathrm{H}$ and ${ }^{13} \mathrm{C}-\mathrm{NMR}$ spectra of 5 were similar to those of 4, except for the appearance of methylene protons and an $\mathrm{sp}^{2}$ carbon at $\mathrm{C}-27\left[\delta_{\mathrm{H}} 5.12(1 \mathrm{H}\right.$, $\left.J=10.5 \mathrm{~Hz}), 5.45(1 \mathrm{H}, J=10.5 \mathrm{~Hz}), \delta_{\mathrm{C}} 122.1\right]$, indicating that 5 is an isomer of 4 . The structure was elucidated by using a single-crystal X-ray diffraction analysis [9] and the ORTEP drawing for 5 is shown in Figure 6 below.

Compounds 1-5 were evaluated for antifeedant activity against the fourth instar larvae of Epilachna vigintioctopunctata at a concentration of $1 \%$. The antifeedant activities of compounds $\mathbf{1}-\mathbf{5}$ are shown in Table 3. Among those compounds, kokosanolide C (2), lacking the ketone group, showed less antifeedant potency, whereas 8,14-secogammacera-14-hydroxy-7-ene-3,21-dione (3) having the hydroxyl group showed the strongest activity, thus, suggested that an oxygenated fuctional group was an important structural component for antifeedant activity.

Figure 6. ORTEP drawing for 5 reproduced from Tjokronegero et al. [9].

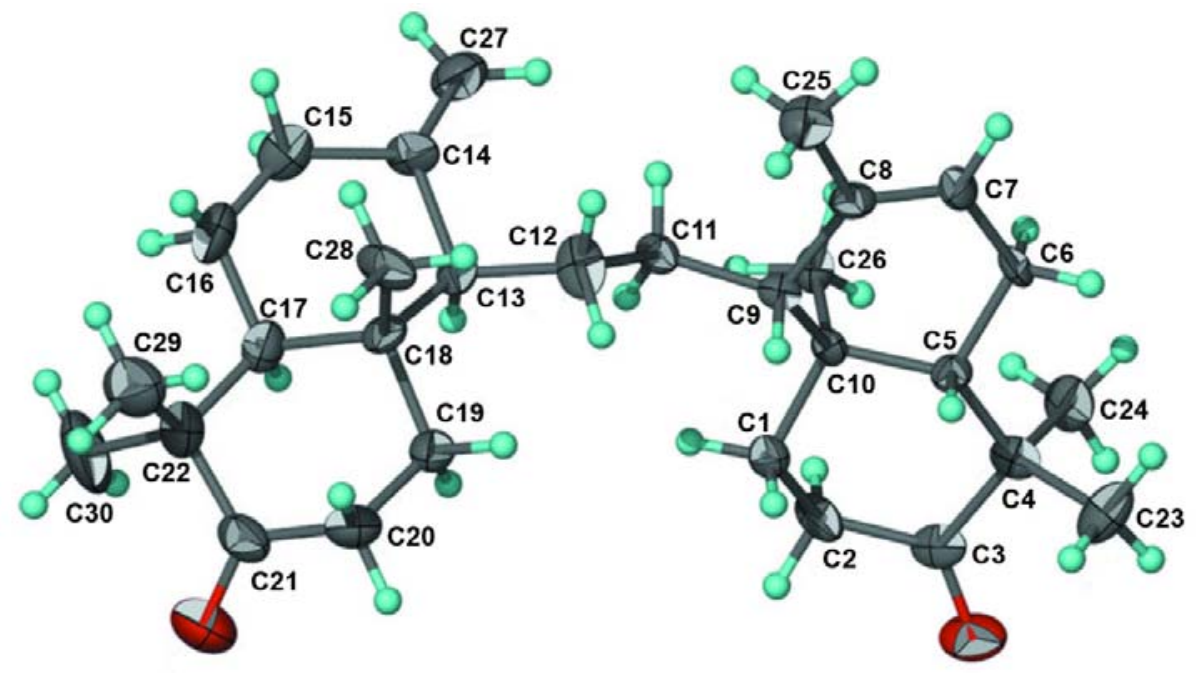


Table 3. Antifeedant activity of compounds $\mathbf{1}-\mathbf{5}$.

\begin{tabular}{lc}
\hline Compound & Activity (\%) \\
\hline Kokosanolide A (1) & 78 \\
Kokosanolide C (2) & 0 \\
Kokosanolide B (3) & 99 \\
8,14-Secogammacera-7,14-diene-3,21-dione (4) & 85 \\
8,14-Secogammacera-7,14(27)-diene-3,21-dione (5) & 56 \\
\hline
\end{tabular}

\section{Experimental}

\subsection{General}

Melting points were measured on an Electrothermal melting point apparatus and are uncorrected. Optical rotations were recorded on a Perkin-Elmer 341 polarimeter. The UV spectra were obtained on a UV Ultraspec 3000 Pro spectrophotometer. The IR spectra were recorded on a Perkin-Elmer 1760X FT-IR in $\mathrm{KBr}$. The mass spectra were recorded with a Mariner Biospectrometry-Finnigan instrument. ${ }^{1} \mathrm{H}$ - and ${ }^{13} \mathrm{C}-\mathrm{NMR}$ spectra were obtained with a JEOL JNM A-500 spectrometer using TMS as internal standard. All ORTEP diagrams were obtained from previous reports. Chromatographic separations were carried out on silica gel 60 (Merck). TLC plates were precoated with silica $\mathrm{GF}_{254}$ (Merck, $0.25 \mathrm{~mm}$ ) and detection was achieved by spraying with $10 \% \mathrm{H}_{2} \mathrm{SO}_{4}$ in ethanol, followed by heating.

\subsection{Plant material}

The bark and seed of L. domesticum cv Kokossan were collected in Cililin District, Bandung, West Java Province, Indonesia in March 2006. The plant was identified by the staff of the Laboratory of Plant Taxonomy, Department of Biology, Padjadjaran University, Indonesia. A voucher specimen (No. 10184) was deposited at the herbarium of the Padjadjaran University.

\subsection{Antifeedant bioassay}

Compounds 1-5 at a concentration of 1\% were subjected to select antifeedant assays on Solanum nigrum leaves against 4th instars larvae of Epilachna vigintioctopunctata. Antifeedant activity (\%AF) was determined by using the equation $\% \mathrm{AF}=(1-$ treatment consumption/control consumption $) \times 100$ [11]. The antifeedant activities of $\mathbf{1}-\mathbf{5}$ at $\mathbf{1 \%}$ concentration are presented in Table 3.

\subsection{Extraction and isolation}

Dried seeds of L. domesticum cv kokossan ( $2 \mathrm{~kg}$ ) were extracted exhaustively with methanol $12 \mathrm{~L}$ at room temperature for 3 days. The resulting methanol extract ( $84 \mathrm{~g}$ ) was partitioned between $n$ hexane $(2.5 \mathrm{~L})$ and $10 \%$ aqueous methanol $(2.5 \mathrm{~L})$ to give an $n$-hexane soluble fraction $(4 \mathrm{~g})$ after removal of the solvent. The $n$-hexane extract was subjected to column chromatography on silica gel 60 using a $n$-hexane and dichloromethane (8:2). The fraction eluted with $n$-hexane-dichloromethane (6:4) was further separated by column chromatography on silica gel ( $n$-hexane-ethyl acetate 7:3) to give $\mathbf{1}$ (150 $\mathrm{mg})$ and 2 (26 mg). 
The dried bark of L. domesticum cv kokossan ( $3 \mathrm{~kg}$ ) was extracted exhaustively with methanol $15 \mathrm{~L}$ at room temperature for 3 days. The methanol extract $(250 \mathrm{~g})$ was partitioned with $n$-hexane $(3 \mathrm{~L})$ and ethyl acetate $(3 \mathrm{~L})$ to give an $n$-hexane soluble fraction $(70 \mathrm{~g})$ and an ethyl acetate soluble fraction (40 g). The ethyl acetate fraction was subjected to vacuum column chromatography on silica gel 60 by using a step gradient of $n$-hexane/ethyl acetate. The fraction eluted with $n$-hexane:ethyl acetate (80:20) was further separated by column chromatography on silica gel using $n$-hexane:ethyl acetate (95:5) to yield an active fraction $(1.5 \mathrm{~g})$. The active fraction was further chromatographed on silica gel using $n$ hexane/acetone (90:10) to give 3 (10 mg), 4 (50 mg) and 5 (24 mg).

Kokosanolide A (1). White needle-like crystals; $[\alpha]^{20}{ }_{\mathrm{D}}+85^{\circ}\left(c \quad 0.5, \mathrm{CHCl}_{3}\right)$; UV $\left(\lambda_{\max }\right.$ in EtOH) $282 \mathrm{~nm}\left(\varepsilon\right.$ 4,600); IR (KBr) $v_{\max } 3,427,1,753,1,709,1,631,1,449$ and $1,389 \mathrm{~cm}^{-1} .{ }^{1} \mathrm{H}-\mathrm{NMR}\left(\mathrm{CDCl}_{3}\right.$, $500 \mathrm{MHz})$, see Table $1 ;{ }^{13} \mathrm{C}-\mathrm{NMR}\left(\mathrm{CDCl}_{3}, 125 \mathrm{MHz}\right)$, see Table 1; LC-ESI-MS data $(\mathrm{m} / \mathrm{z}$ 500.8093, $\left.[\mathrm{M}+\mathrm{H}]^{+}\right)$.

Kokosanolide $C$ (2). Colorless needle-like crystals; $[\alpha]^{20}{ }_{\mathrm{D}}+96^{\circ}\left(\mathrm{c} 0.5, \mathrm{CHCl}_{3}\right)$; $\mathrm{UV}\left(\lambda_{\max }\right.$ in EtOH$)$ $275 \mathrm{~nm}\left(\varepsilon\right.$ 4,500); IR (KBr) $v_{\max } 3,563 \mathrm{~cm}^{-1}, 1,758 \mathrm{~cm}^{-1}, 17,04 \mathrm{~cm}^{-1} .{ }^{1} \mathrm{H}-\mathrm{NMR}\left(\mathrm{CDCl}_{3}, 500 \mathrm{MHz}\right)$, see Table $1 ;{ }^{13} \mathrm{C}$-NMR $\left(\mathrm{CDCl}_{3}, 125 \mathrm{MHz}\right)$, see Table 1 .

Kokosanolide $B$ (3). cubic crystals; $[\alpha]^{20}{ }_{\mathrm{D}}-18.5^{\circ}$ (c 01.0, MeOH); IR $(\mathrm{KBr}) v_{\max } 3,749,1,705,1,384$ and $1,261 \mathrm{~cm}^{-1} .{ }^{1} \mathrm{H}-\mathrm{NMR}\left(\mathrm{CDCl}_{3}, 500 \mathrm{MHz}\right)$, see Table $2 ;{ }^{13} \mathrm{C}-\mathrm{NMR}\left(\mathrm{CDCl}_{3}, 125 \mathrm{MHz}\right)$, see Table 2. LC-ESI-MS data $\left(\mathrm{m} / \mathrm{z}\right.$ 456.6892, $\left.[\mathrm{M}+\mathrm{H}]^{+}\right)$.

8,14-Secogammacera-7,14-diene-3,21-dione (4). Needle-like crystals; $[\alpha]^{20}-8^{\circ}$ (c 0.5, MeOH); IR $(\mathrm{KBr}) v_{\max } 1,708,1,662,1,430,1,360 \mathrm{~cm}^{-1} .{ }^{1} \mathrm{H}-\mathrm{NMR}\left(\mathrm{CDCl}_{3}, 500 \mathrm{MHz}\right)$, see Table $2 ;{ }^{13} \mathrm{C}-\mathrm{NMR}$ $\left(\mathrm{CDCl}_{3}, 125 \mathrm{MHz}\right)$, see Table 2. LC-ESI-MS data $\left(\mathrm{m} / \mathrm{z} 438.3745,[\mathrm{M}+\mathrm{H}]^{+}\right)$.

8,14-Secogammacera-7,14(27)-diene-3,21-dione (5). Needle-like crystals; IR ( $\mathrm{KBr}) v_{\max } 1,667,1,454$ and $1,384 \mathrm{~cm}^{-1} .{ }^{1} \mathrm{H}-\mathrm{NMR}\left(\mathrm{CDCl}_{3}, 500 \mathrm{MHz}\right), \delta_{\mathrm{H}}(\mathrm{ppm}), 0.95(3 \mathrm{H}, \mathrm{s}), 0.97(3 \mathrm{H}, \mathrm{s}), 1.04(3 \mathrm{H}, \mathrm{s}), 1.08$ $(3 \mathrm{H}, \mathrm{s}), 1.09(3 \mathrm{H}, \mathrm{s}), 1.10(3 \mathrm{H}, \mathrm{s}), 1.20(1 \mathrm{H}, \mathrm{m}), 1.22(3 \mathrm{H}, \mathrm{s}), 1.24(1 \mathrm{H}, \mathrm{dd}, J=5,10 \mathrm{~Hz}), 1.33(1 \mathrm{H}$, $\mathrm{dd}, J=7,10 \mathrm{~Hz}), 1.40(1 \mathrm{H}, \mathrm{m}), 1.46(1 \mathrm{H}, \mathrm{m}), 1.50(1 \mathrm{H}, \mathrm{m}), 1.59(1 \mathrm{H}, \mathrm{dd}, J=5,7 \mathrm{~Hz}), 1.63(1 \mathrm{H}, \mathrm{m})$, $1.65(1 \mathrm{H}, \mathrm{m}), 1.72(3 \mathrm{H}, \mathrm{s}), 1.79(1 \mathrm{H}, \mathrm{m}), 1.83(1 \mathrm{H}, \mathrm{m}), 1.93(1 \mathrm{H}, \mathrm{m}), 2.04(1 \mathrm{H}, \mathrm{m}), 2.09(1 \mathrm{H}, \mathrm{m}), 2.15$ $(1 \mathrm{H}, \mathrm{m}), 2.24(1 \mathrm{H}, \mathrm{m}), 2.35(1 \mathrm{H}, \mathrm{m}), 2.40(1 \mathrm{H}, \mathrm{m}), 2.45(1 \mathrm{H}, \mathrm{m}), 2.70(1 \mathrm{H}, \mathrm{m}), 5.12(1 \mathrm{H}$, $J=10.5 \mathrm{~Hz}), 5.43(1 \mathrm{H}, \mathrm{m}), 5.45(1 \mathrm{H}, J=10.5 \mathrm{~Hz}) ;{ }^{13} \mathrm{C}-\mathrm{NMR}\left(\mathrm{CDCl}_{3}, 125 \mathrm{MHz}\right), \delta_{\mathrm{C}}(\mathrm{ppm}) ; 13.5$, 22.3, 22.5, 24.2, 25.1, 30.1, 34.8, 34.9, 36.7, 38.5, 47.6. 51.2, 51.6, 55.6, 122.1, 135.3, 216.9, 217.0.

\section{Conclusions}

The methanolic extract from the dried seed and bark of Lansium domesticum cv kokossan yield two tetranortriterpenoids - kokosanolide $\mathrm{A}$ and $\mathrm{C}$ - and one onoceranoid-type triterpenoid, kokosanolide $\mathrm{B}$, along with two onoceranoid-type triterpenoids; 8,14-secogammacera-7,14-diene-3,21-dione and a mixture of 8,14-secogammacera-7,14(27)-diene-3,21-dione and 8,14-secogammacera-7,14-diene-3,21dione (1.5:0.5). The results of this study provide a basis for futher phytochemical studies on the Lansium plants. This study also suggests that the Lansium plants contain potent antifeedant compounds for further application. 


\section{Acknowledgments}

We are grateful to the Directorate General of Higher Education, Ministry of National Education, Indonesia and I-MHERE project of Padjadjaran University for financial support. We thank Mr. Ahmad Darmawan and Mrs. Sofa Fajriah in the Research Center for Chemistry, Indonesian Science Institute, for NMR and LC-ESI-MS measurements. We are grateful to $\mathrm{Ng}$ Seik Weng at Department of Chemistry, Faculty of Science, University of Malaya, Kuala Lumpur, Malaysia for X-ray measurement.

\section{References}

1. Omar, S.; Marcotte, M.; Fields, P.; Sanchez, P.E.; Poveda, L.; Matta, R.; Jimenez, A.; Durst, T.; Zhang, J.; Kinnon, M.; Leaman, D.; Arnason, J.T.; Philogene, J.R. Antifeedant activities of triterpenoids isolated from tropical Rutales. J. Stored Prod. Res. 2007, 43, 92-96.

2. Champagne, D.E.; Koul, O.; Isman, M.B.; Scudder, G.G.E.; Towers, G.H.N. Biological Activity of Limonoids from the Rutales. Phytochemistry 1992, 31, 377-394.

3. Saewan, N.; Sutherland, J.D.; Chantrapromma, K. Antimalarial tetranorterpenoids from the seeds of Lansium domesticum Corr. Phytochemistry 2006, 67, 2288-2293.

4. Nishizawa, M.; Nademoto, Y.; Sastrapradja, S.; Shiro, M.; Hayashi, Y. New tetranortriterpenoid from the seeds of Lansium domesticum. Phytochemistry 1988, 27, 237-239.

5. Nishizawa, M.; Nademoto, Y.; Sastrapradja, S.; Shiro, M.; Hayashi, Y. Structure of Dukonolides, Bitter Principles of Lansium domesticum. J. Org. Chem. 1985, 50, 5487-5490.

6. Nishizawa, M.; Nishide, H.; Hayashi, Y. the structure of lansioside A: A novel triterpenes glycoside with amino-sugar from Lansium domesticum. Tetrahedron Lett. 1982, 23, 1349-1350.

7. Mayanti, T.; Supratman, U.; Mukhtar, M.R.; Awang, K.; Ng, S.W. Kokosanolide from the seed of Lansium domesticum Corr. Acta Cryst. 2009, E65, o750.

8. Supratman, U.; Mayanti, T.; Awang, K.; Mukhtar, M.R.; Ng, S.W. 14-Hydroxy-8,14secogammacera-7-ene-3,21-dione from the bark of Lansium domesticum Corr. Acta Cryst. 2010, E66, o1621.

9. Tjokronegoro, R.; Mayanti, T.; Supratman, U.; Mukhtar, M.R.; Ng, S.W. 8,14-Secogammacera7,14(27)-diene-3,21-dione-8,14-secogammacera-7,14-diene-3,21-dione (1.5/0.5) from the bark of Lansium domesticum Corr. Acta Cryst. 2009, E65, o1448.

10. Tanaka, T.; Ishibashi, M.; Fujimoto, H.; Okuyama, E.; Koyana, T.; Kowithayakorn, T.; Hayashi, M.; Komiyama, K. New onoceranoid triterpene constituents from Lansium domesticum. J. Nat. Prod. 2002, 65, 1709-1711.

11. Schwinger, M.; Ehhammer, B.; Kraus, W. Methodology of the Epilachna Varivestis Bioassay of Antifeedants Demonstarted with Some Compounds from Azadirachta indica and Melia azedarach. In Proceedings of 3rd International Neem Conference, Nairobi, Kenya, 10 July 1986.

Sample Availability: Samples of the compounds $\mathbf{1 - 5}$ are available from the authors.

(C) 2011 by the authors; licensee MDPI, Basel, Switzerland. This article is an open access article distributed under the terms and conditions of the Creative Commons Attribution license (http://creativecommons.org/licenses/by/3.0/). 